\title{
The Design of Hybrid Power Supply AGV Trolley System for Agriculture
}

\author{
Jingping Zhang, Shiquan Shao* \\ College of Electrical \& Information Engineering, Southwest Minzu University, Chengdu, China \\ Email: 1546464170@qq.com
}

\begin{abstract}
The AGV (Automatic Guided Transport Vehicle) is used more and more widely in the modern agriculture. The power supply system of the AGV trolley is an indispensable part of ensuring the operation of the machine. According to the actual use of the AGV car in this paper, the power consumption of the car is analyzed, and the power system of the AGV car is designed according to the power usage, so that the AGV car can meet the power demand under different loads. This paper uses MATLAB/SIMULINK software to simulate and verify the normal operation of the hybrid power supply AGV car.
\end{abstract}

Keywords: AGV car, hybrid power system, efficient

\section{Introduction}

Agriculture has always been the foundation of China. It is the development goal of modern agriculture to promote the automation of agricultural production and reduce the physical labor intensity of farmers [1]. The development of agricultural Internet of things enables agricultural production to continuously integrate computer network technology, Internet of things technology, audio and video technology, wireless communication technology, etc., so as to realize intelligent and automatic agriculture [2-4].

AGV car is an autonomous vehicle controlled by computer, which can complete cruise, pick up and deliver goods according to operation requirements and plans. It has the advantages of high transportation efficiency, energy saving, reliable operation and flexible transportation [5-7]. As a key part of production and transportation, AGV car's power system and power supply system are the key factors to ensure the safe, stable and efficient operation of AGV car [8-9]. For AGV power supply system, traditional methods include lithium battery power supply [10], battery power supply [11] and ultracapacitor power supply [12].

This paper firstly analyzes three kinds of AGV trolley power supply systems, and designs a hybrid power supply system based on the specific application of AGV trolley in agriculture, so that AGV trolley can meet the requirements of multi-working conditions and improve the working efficiency and service life of AGV trolley.

\section{Overview of Traditional AGV Power Supply System}

\subsection{Lithium Battery Power Supply}

Lithium batteries were mainly used in the consumer electronics market at the earliest. In recent years, with the progress of science and technology, the cost reduction, and the increasingly strong demand for green new energy, lithium batteries have been applied more and more widely. Performance indexes of lithium battery [13] are shown in tab 1.

Table 1. Performance indicators of lithium batteries

\begin{tabular}{cccccccc}
\hline $\begin{array}{c}\text { Specific } \\
\text { energy/ } \\
(W h / K g)\end{array}$ & $\begin{array}{c}\text { Specific } \\
\text { energy/ } \\
(W h / L)\end{array}$ & $\begin{array}{c}\text { specific } \\
\text { power/ } \\
(W / K g)\end{array}$ & $\begin{array}{c}\text { cycles } \\
(\mathrm{DOD} 80 \%)\end{array}$ & $\begin{array}{c}\text { Monomer } \\
\text { voltage/V }\end{array}$ & $\begin{array}{c}\text { Battery } \\
\text { module } \\
\text { capacity/Ah }\end{array}$ & $\begin{array}{c}\text { Battery } \\
\text { module } \\
\text { quality } / \mathrm{kg}\end{array}$ & $\begin{array}{c}\text { Cell module } \\
\text { voltage/V }\end{array}$ \\
\hline $100-250$ & $250-360$ & $250-340$ & 1000 & 3.7 & 400 & 14.4 & 3.2 \\
\hline
\end{tabular}


Lithium batteries have very low discharge, no memory effect, high specific energy, high output power, fast charging, long cycle life, can fully meet the needs of AGV car, and simple maintenance. In practical applications, when lithium ion batteries are below zero, the internal resistance of capacity will change greatly. Therefore, when using lithium batteries to power AGV cars in low-temperature areas, it is necessary to add insulation measures. If the temperature is too high, the service life of lithium batteries will be lost.

\subsection{Battery Power Supply}

Conventional AGVs are usually powered by batteries. When the AGV car detects that the residual power is not enough to maintain the basic operation, the operating system will control the car to automatically travel to the charging station for charging. The performance index of battery [14] is shown in tab 2 .

Table 2. Performance indicators of batteries

\begin{tabular}{cccccccc}
\hline $\begin{array}{c}\text { Specific } \\
\text { energy/ } \\
(W h / K g)\end{array}$ & $\begin{array}{c}\text { Specific } \\
\text { energy/ } \\
(W h / L)\end{array}$ & $\begin{array}{c}\text { specific } \\
\text { power/ } \\
(W / K g)\end{array}$ & $\begin{array}{c}\text { cycles } \\
(\mathrm{DOD} 80 \%)\end{array}$ & $\begin{array}{c}\text { Monomer } \\
\text { voltage/V }\end{array}$ & $\begin{array}{c}\text { Battery } \\
\text { module } \\
\text { capacity/Ah }\end{array}$ & $\begin{array}{c}\text { Battery } \\
\text { module } \\
\text { quality/kg }\end{array}$ & $\begin{array}{c}\text { Cell } \\
\text { module } \\
\text { voltage/V }\end{array}$ \\
\hline $30-50$ & $60-75$ & $90-200$ & 400 & $2.1-2.5$ & 150 & 42 & 12 \\
$38-40$ & $90-110$ & $150-180$ & 500 & $2.0-2.5$ & 150 & 47.6 & 12 \\
\hline
\end{tabular}

Battery is suitable for low current slow charge slow down, need to add water regularly, long time do not need timely charging. In most cases, $\mathrm{AGV}$ car needs medium rate discharge and high current charge, so the use of battery alone to supply power for AGV car is less than small load, long time work, long time charge, and has certain requirements for the working environment. Therefore, if the emergent conditions in the process of using or not timely maintenance, such as heavy rain weather, insufficient depth of small current discharge, rechargeable, battery internal water shortage, long-term use will appear the phenomenon of battery plate vulcanizing, greatly shorten the service life of the battery, after the maintenance process and capacity loss is not easy to recover in AGV battery power supply system is not widely used in one of the reasons.

\section{$2.3 \quad$ Supercapacitor Power Supply}

An ultracapacitor, also known as electrochemical capacitors, electric double layer capacitors, gold capacitor, farah capacitance, developed from $\mathrm{s}$ and eighty $\mathrm{s}$ a electrochemical energy storage by polarization electrolyte components, it is different from the traditional chemical power source, is a kind of between conventional capacitors and batteries, with special performance of power supply. The performance indexes of ultracapacitors [15] are shown in tab 3.

Table 3. Performance indicators of supercapacitors

\begin{tabular}{|c|c|c|c|c|c|c|c|}
\hline $\begin{array}{l}\text { Specific } \\
\text { energy/ } \\
(W h / K g)\end{array}$ & $\begin{array}{l}\text { Specific } \\
\text { energy/ } \\
(W h / L)\end{array}$ & $\begin{array}{l}\text { specific } \\
\text { power/ } \\
(W / K g)\end{array}$ & $\begin{array}{c}\text { cycles } \\
(\text { DOD } 80 \%)\end{array}$ & $\begin{array}{l}\text { Monomer } \\
\text { voltage/V }\end{array}$ & $\begin{array}{c}\text { Super } \\
\text { capacitor } \\
\text { module } \\
\text { capacity/Ah }\end{array}$ & $\begin{array}{c}\text { Super } \\
\text { capacitor } \\
\text { module } \\
\text { quality/kg } \\
\end{array}$ & $\begin{array}{c}\text { Super } \\
\text { capacitor } \\
\text { module } \\
\text { capacity/V }\end{array}$ \\
\hline 40 & 71.47 & 2314 & $>30000$ & $2.2-3.6$ & 65 & 90 & $15-18$ \\
\hline
\end{tabular}

Super capacitor charging speed and large current discharge capacity, high energy conversion efficiency, high power density, charge and discharge circuit is simple, raw material products, production, use, storage, and there is no pollution in the process of dismantling, is the ideal of green power, expensive materials is the main reason for the development of super capacitor. The disadvantage of ultracapacitors is that they store less energy for the same weight, so they are mainly used in light and simple AGV systems. 


\section{Hybrid Power AGV Vehicle System}

By comparing the performance indexes of three common power supply modes and other factors, this paper adopts the hybrid power supply mode of battery and ultracapacitor to supply power for AGV car. The ultracapacitor provides the power to discharge large current when the car is started or unloaded, and the battery provides the power to run smoothly after the car is started. This method can not only avoid the shock of large current discharge and prolong the service life of the battery, but also make the mixed power supply system meet the demand of high energy density.

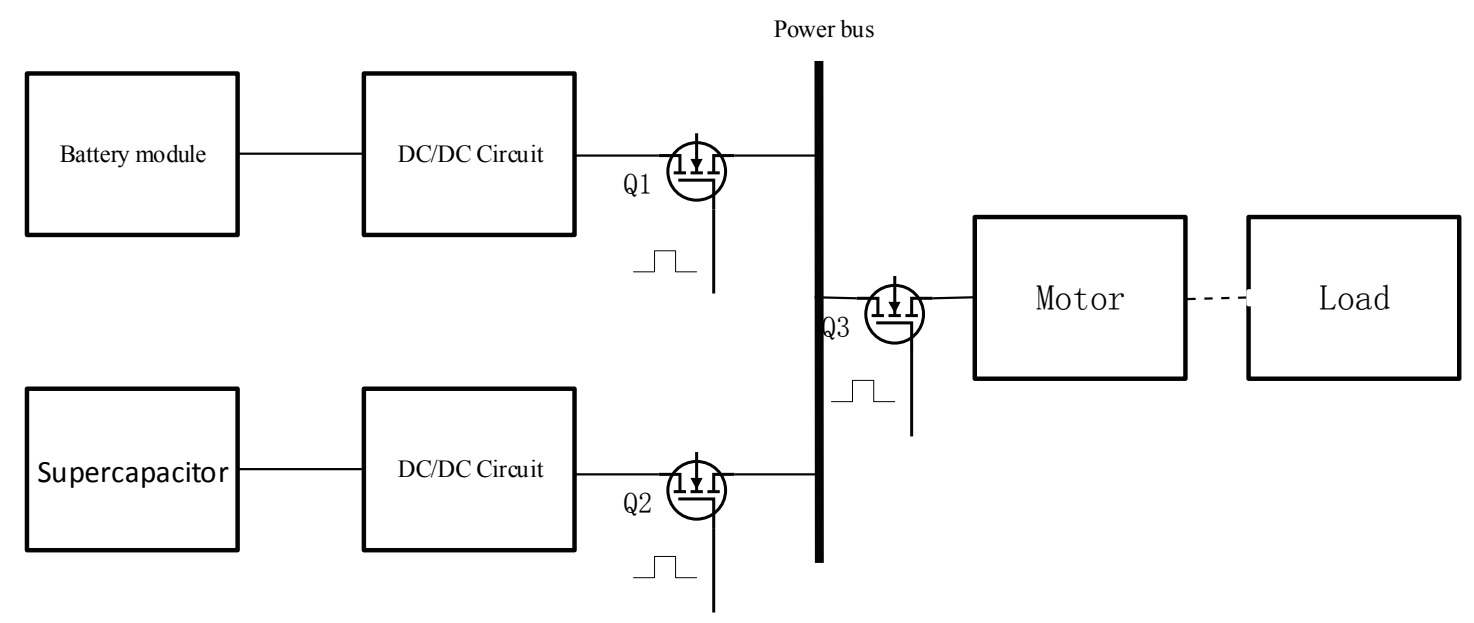

Figure 1. AGV car with hybrid power supply system

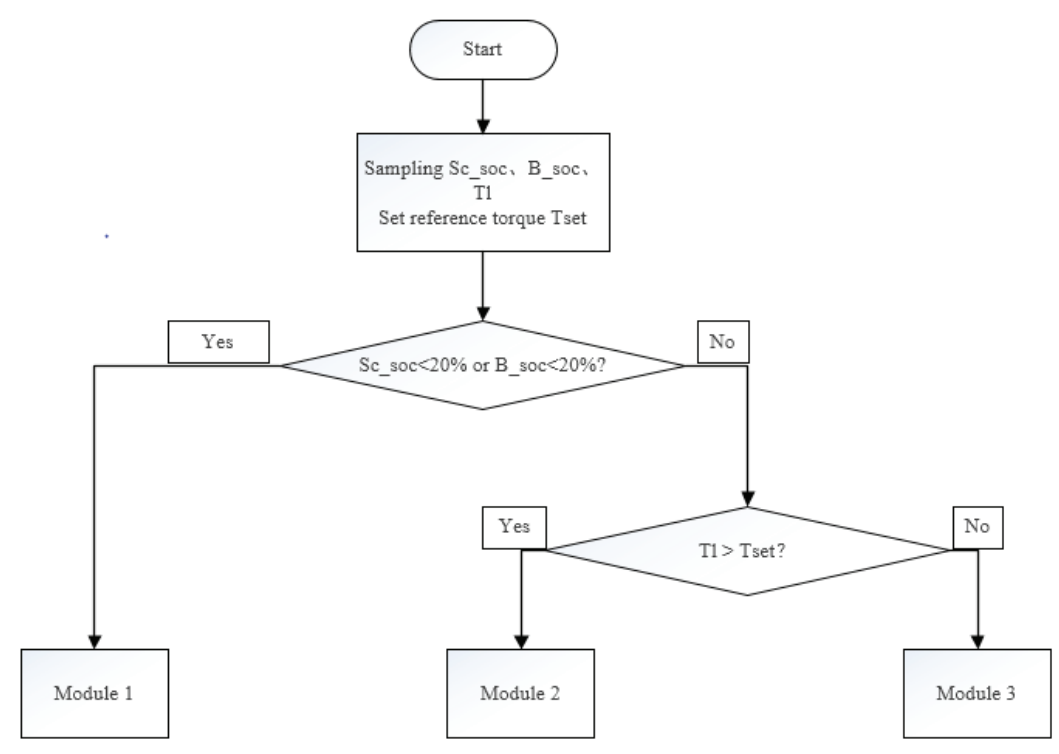

Figure 2. Algorithmic flow chart of AGV car with hybrid power supply system

In modern agriculture, AGV trolleys are often used as tools for handling. According to the change of actual load, the design structure of AGV vehicle with hybrid power supply is shown in figure 1 . The battery and the ultracapacitor are connected in parallel to the power bus after being converted to appropriate voltage by the $\mathrm{DC} / \mathrm{DC}$ circuit module, and the bus back end is connected to the motor to drive the external load. According to the change of load of the system, the system is divided into three working modes by controlling the actions of switch Q1 and Q2:

Mode 1: when super capacitor or battery charge state is detected to be too low, AGV car charging; 
Mode 2: when the load of AGV car is light or the road is stable, the power demand of the car is small. Switch tube Q1 is closed and Q2 is disconnected.

Mode 3: when the load of AGV car increases or the road is potholed, the power demand of the car is large. Switch tube Q2 is closed and Q1 is disconnected. Ultracapactance is discharged with large current to achieve large current output.

The flow chart of system control algorithm is shown in fig 2.

\section{Simulation of Hybrid Power AGV Vehicle System}

Hybrid power AGV vehicle system includes hybrid power supply, voltage regulator circuit, motor drive circuit and motor module. The hybrid power supply consists of ultracapacitor and battery. The control system can switch the power supply mode of ultracapacitor and battery by detecting the change of AGV car load. The voltage regulator circuit converts the output voltage of ultracapacitor and battery to a constant dc voltage. The drive circuit takes the output voltage of the voltage regulator circuit as input to drive the work of the motor. The system simulation structure diagram is shown in the following fig 3 .

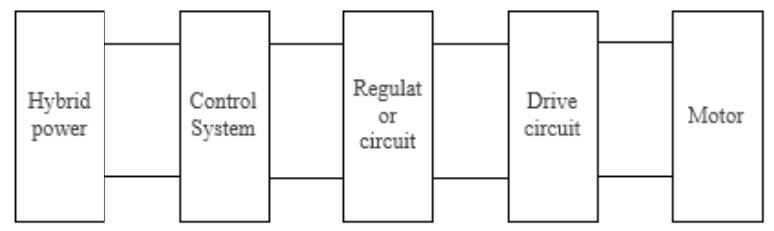

Figure 3. Block diagram of hybrid power supply system for AGV car

According to the structural block diagram of AGV car system designed in figure 3 , the hybrid powered AGV car was modeled by MATLAB/SIMULINK software, and the simulation modlel was shown in fig 4 .

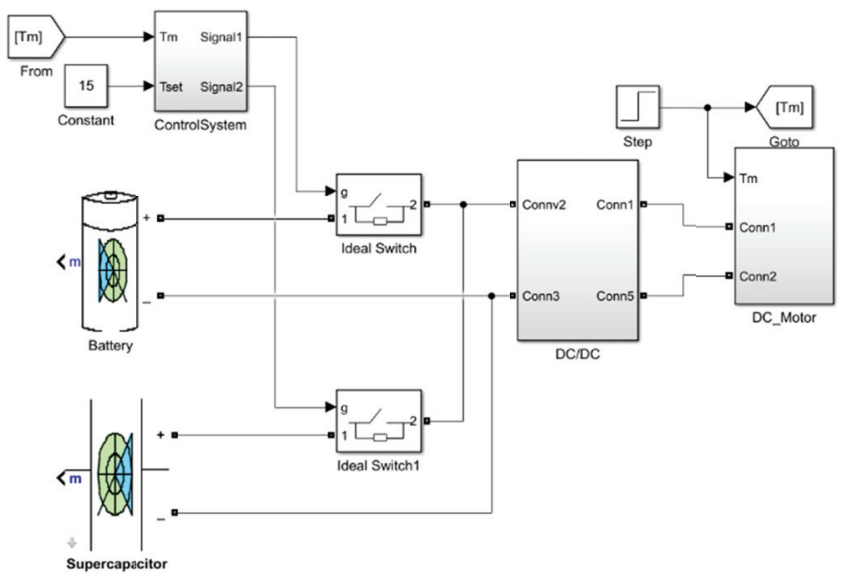

Figure 4. Hybrid power supply AGV car simulation model

\subsection{Hybrid Power Module}

The ultracapacitor and battery model built in MATLAB/SIMULINK are adopted in the simulation system. The battery capacity of the battery is set at $0.5 \mathrm{ah}$ and the rated voltage is set at $36 \mathrm{~V}$. The battery capacity of the battery is calculated as follows:

$$
W_{b \mathrm{t}}=0.5 \times 36 \times 60 \times 60=64800 \mathrm{~J}
$$

Meanwhile, set the capacitance value of the ultracapacitor as $100 \mathrm{~F}$ and the rated voltage as $36 \mathrm{~V}$, and calculate the battery capacity of the ultracapacitor as follows: 


$$
W_{\mathrm{SC}}=\frac{1}{2} c U^{2}=\frac{1}{2} \times 100 F \times 36^{2}=64800 J
$$

\subsection{Control System Module}

The Control System module in figure 4 is the system Control System module. According to the algorithm flow chart of AGV car hybrid power supply system designed in FIG. 2, when the system starts up, the ultracapacitor and battery are tested for the state of charge. When the charge state of the ultracapacitor and battery is less than 20\%, AGV car alarm indicates the need to charge; when the ultracapacitor and battery charge state is more than $20 \%$, the AGV car runs normally. During normal operation, the load condition of the system is tested and the reference torque is set to $15 \mathrm{n} \cdot \mathrm{m}$. When the load torque is less than the reference torque, the battery will supply power to the motor. When the load torque is greater than the reference torque, the ultracapacitor provides fast power to the motor to maintain the high power demand of the system.

\subsection{Voltage Regulator Circuit}

The DC voltage regulator circuit converts the output voltage of the supercapacitor and the battery into a constant dc voltage, which can meet the voltage requirement of the motor when it works normally. In the system simulation model shown in figure 4, the DC/DC module is a constant voltagie and current limiting circuit, which adopts the method of double closed-loop control to realize the conversion of the output voltage of the supercapacitor and the battery, and the MATLAB simulation circuit model is shown in fig 5 .
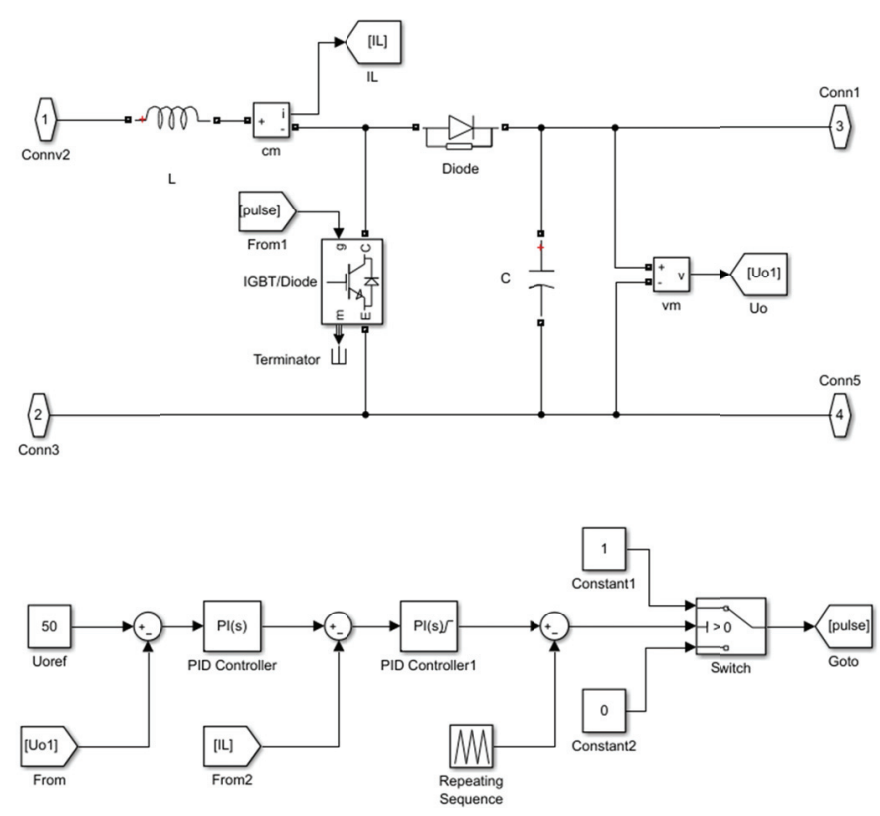

Figure 5. Direct current manostat circuit

\subsection{Motor System}

DC_Motor in the hybrid power AGV vehicle simulation model shown in fig 6 consists of motor drive circuit and dc motor. In the motor control system, frequency conversion control is used to adjust the motor speed. The rotor position signal is detected by hall components and used as feedback signal to control the working frequency of inverter bridge to realize the adjustment of motor speed. The relevant circuit is shown in the figure below. 


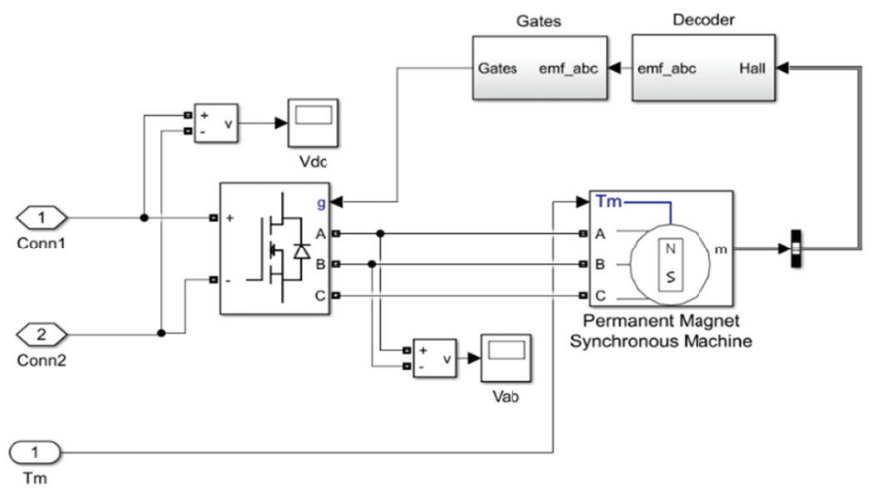

Figure 6. Motor control system

\section{$5 \quad$ The Simulation Results}

Fig 7 (a) shows the output voltage waveform of the voltage regulator circuit. The output of battery and ultracapacitor is the input voltage of the dc voltage regulator circuit, and the initial voltage is $36 \mathrm{~V}$. When the load torque of the dc motor is $3 \mathrm{~s}$, it rises from 10n. m to 20n. m. As shown in FIG. 7 (a), the output voltage of the voltage regulator circuit is constant at 50V. FIG.7 (b) shows the output current waveform of the voltage regulator circuit. The output current rises from $7 \mathrm{~A}$ to $11.7 \mathrm{a}$ at $3 \mathrm{~s}$, and the output power increases.

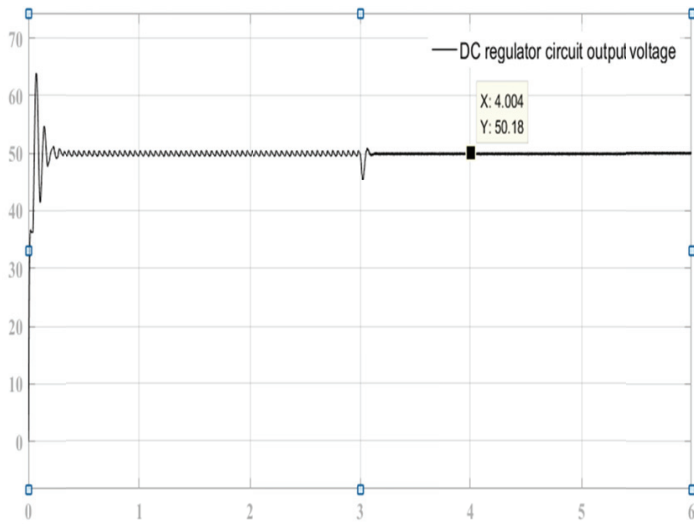

(a) Output voltage of DC/DC circuit

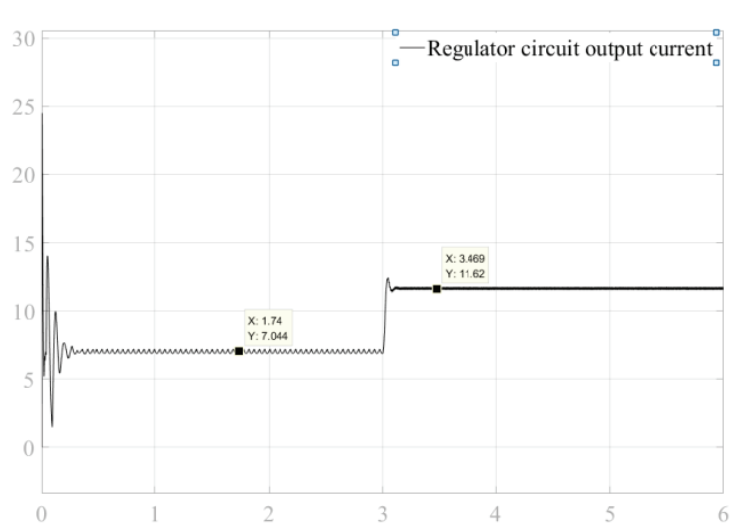

(b) Output current of DC/DC circuit

Figure 7. Simulated output waveform

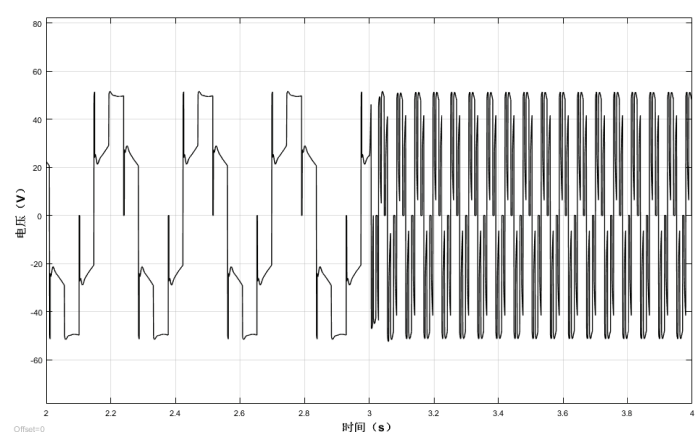

Figure 8. The input voltage of the motor

FIG. 8 shows the waveform of the input voltage of the motor. At $3 \mathrm{~s}$, the motor torque changes, and the 
frequency of the input voltage of the motor increases from $3.7 \mathrm{hz}$ to $17.8 \mathrm{hz}$, realizing the process of motor frequency conversion and speed regulation.

\section{Conclusion}

With the continuous improvement of AGV vehicle performance, the demand for power is changing constantly. This paper analyzes the output power status of AGV car power supply according to the load change of AGV car in practice. By analyzing the physical characteristics and charging and discharging characteristics of battery and ultracapacitor, the AGV vehicle system with battery and ultracapacitor as power input is designed, and each working mode is analyzed according to the working state of AGV vehicle system. MATLAB is used to simulate the system. According to the simulation results, the hybrid AGV vehicle system has better performance than the traditional single power supply system.

Acknowledgements. The work of this paper is supported by the Southwest Minzu University Graduate Innovative Research Project (Master Program CX2019SZ26). A special acknowledgement should give to Southwest Minzu University for its experimental conditions and technical support.

\section{References}

1. Xiong L, Sun S, Xiao M. Agricultural Machinery Automation and Intelligent Research and Application[J]. IOP Conference Series Materials Science and Engineering, 2018, 452:042077.

2. Li J, Guo M, Gao L. Application and innovation strategy of agricultural Internet of Things[J]. Transactions of the Chinese Society of Agricultural Engineering, 2015.

3. Zhao Y L. Researches on countermeasures and the status quo of agricultural industrialized cluster in Henan Province.[J]. Asian Agricultural Research, 2010, 2(11):26-29.

4. Huang S J, Dai S H, Su J L, et al. Design of a contactless power supply system with dual output capability for AGV applications[C]// Consumer Electronics. 2017.

5. Srivastava S C, Choudhary A K, Kumar S, et al. Development of an intelligent agent-based AGV controller for a flexible manufacturing system[J]. International Journal of Advanced Manufacturing Technology, 2008, $36(7-8): 780$.

6. Archetti F, Sciomachen A. Development analysis and simulation of Petri net models: an application to AGV systems[C]// Operations Research Models in Flexible Manufacturing Systems. 1989.

7. Wang C, Lin W, Jian Q, et al. Development of a vision navigation system with Fuzzy Control Algorithm for Automated Guided Vehicle[C]// IEEE International Conference on Information \& Automation. 2015.

8. Huang S J, Dai S H, Su J L, et al. Design of a contactless power supply system with dual output capability for AGV applications[C]// Consumer Electronics. 2017.

9. Li S, Zhang C. Study on Battery Management System and Lithium-ion Battery[C]// International Conference on Computer \& Automation Engineering. 2010.

10. FERNANDEZ, VALENCIANO, MUNOZ. The use of activated carbon and graphite for the development of lead-acid batteries for hybrid vehicle applications[J]. Journal of Power Sources, 2010, 195(14):4458-4469.

11. Yu Z, Zinger D, Bose A. An innovative optimal power allocation strategy for fuel cell, battery and supercapacitor hybrid electric vehicle[J]. Journal of Power Sources, 2011, 196(4):2351-2359.

12. Skundin A M, Efimov O N, Yarmolenko O V. The state-of-the-art and prospects for the development of rechargeable lithium batteries[J]. Cheminform, 2010, 33(39):226-226.

13. Feder D O, Croda T G, Champlin K S, et al. Field and laboratory studies to assess the state of health of valve-regulated lead acid batteries. I Conductance/capacity correlation studies[C]// International Telecommunications Energy Conference. 1992.

14. Xuan L, Yongli L, Xiaoyong C. Nonlinear Control Algorithm for Super Capacitor Energy Storage System Based on Exact Linearization Theory[J]. Transactions of China Electrotechnical Society, 2016. 